\title{
PRES in pregnancy: MRI and it's role in decision making
}

\author{
Shalini Mahana Valecha*, Sara Azad Koshish, Manisha Rajesh Gandhewar, Divija Dhingra
}

Department of Obstetrics and Gynaecology, Employees State Insurance Post Graduate Institute of Medical Sciences and Research \& Model Hospital, Central Road, MIDC, Andheri East, Mumbai-400093, India

Received: 21 September 2013

Accepted: 8 October 2013

\section{*Correspondence:}

Dr. Shalini Mahana Valecha,

E-mail: shalini.mahana@gmail.com

(C) 2013 Valecha SM et al. This is an open-access article distributed under the terms of the Creative Commons Attribution Non-Commercial License, which permits unrestricted non-commercial use, distribution, and reproduction in any medium, provided the original work is properly cited.

\begin{abstract}
Posterior reversible encephalopathy syndrome (PRES) is an alarming clinic-neuro-radiological syndrome accompanying various clinical conditions, presenting with headache, encephalopathy, seizures, cortical visual disturbances or blindness. The lesions in PRES are thought to be due to vasogenic oedema, predominantly in the water-shed regions of the posterior cerebral hemisphere, fortunately, completely reversible with management of the primary condition. We report a case of primigravida with 26 weeks pregnancy, who presented with acute, severe, in-tractable, throbbing headache, tingling sensation in the posterior neck and upper shoulder region, photophobia, nausea and mild pre-eclampsia. Standard therapy did not relieve the headache, BP remained fluctuant, so migraine/some intra-cranial pathology was suspected. MRI is the gold-standard diagnostic modality. It revealed the classical acute PRES picture. PRES implies breaching of the blood brain barrier, resultant cerebral edema and potential for further intra-cranial events of serious proportions. Notably, PRES may be seen with normotension. Pregnancy was terminated un-eventfully, recovery was prompt and complete. Two weeks later, the patients showed marked improvement clinically and neuro-imaging features of PRES had dis-appeared.
\end{abstract}

Keywords: PRES, Pre-eclampsia, Cerebral edema, MRI, Pregnancy

\section{INTRODUCTION}

Posterior Reversible Encephalopathy Syndrome (PRES) refers to a rare clinico-radiologic entity introduced as late as 1996 by Hinchey et al, ${ }^{1}$ where a neurotoxic state is coupled with a unique CT or MRI picture. Recognised in the setting of a number of complex conditions including pre-eclampsia /eclampsia, it has characteristic features on neuro-imaging and non-specific symptoms comprising headache, confusion, encephalopathy, cortical visual disturbances or blindness and seizures. ${ }^{2,3}$

\section{CASE REPORT}

We report a case of primigravida with 26 weeks pregnancy, presenting with acute, severe, in-tractable, throbbing headache, tingling sensation in the posterior neck and upper shoulder region, photophobia, nausea and volatile blood pressure. Blood pressure remained fluctuating between $110 / 70$ to $160 / 100$ values with min albuminuria, mild edema feet. Fundoscopy was unremarkable. In view of her fluctuating blood pressure she was started on anti-hypertensives responded to Labetalol, Alpha methyl dopa but headache worsened. Typical distribution of symptoms created a suspicion of migraine or some intra-cranial pathology. MRI scan revealed the classical acute PRES picture of diffuse, abnormal signal intensities, involving predominantly, deep white matter in the region of the occipital lobes (Figure 1). Blood investigations were normal. Pregnancy was terminated un-eventfully. 
Symptoms dis-appeared with remarkable speed and neuro-imaging features of PRES reversed miraculously.

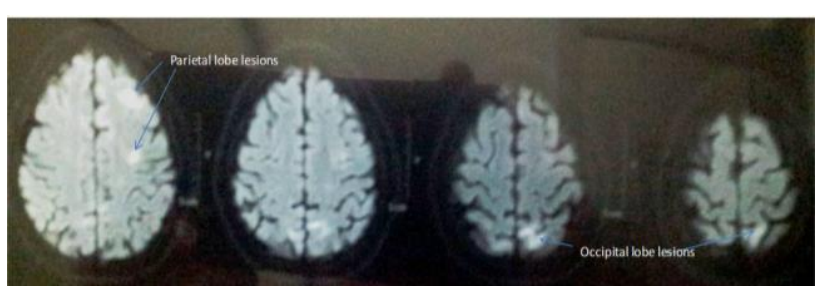

Figure 1: MRI showing classical picture of acute PRES- T2 weighted images showing hyperintensities in occipital and parietal lobes characteristic of posterior reversible encephalopathy syndrome.

\section{DISCUSSION}

Posterior reversible encephalopathy syndrome, also termed reversible posterior leukoencephalopathy syndrome or posterior cerebral oedema syndrome is a newly recognized clinico-neuro-radiological syndrome, affecting predominantly the white matter of the posterior cerebral hemispheres.

PRES is a grave complication accompanying a myriad of obstetric and medical conditions, chiefly, hypertension, preeclampsia/eclampsia and HELLP syndrome. Others being hypertensive encephalopathy, nephropathy, following immunosuppressive or anticancer medication (methylprednisolone, cyclosporine and tacrolimus), systemic lupus, amyloid angiopathy, Henoch-Schonlein syndrome, hemolytic uremic syndrome, sepsis (gram positive), shock. Headache is typically acute, severe, intractable, associated with visual disturbances, seizures, altered consciousness, nausea, vomiting, focal neurologic deficits, stupor and coma, all indicative of multi-focal intra-cranial events. ${ }^{4,5}$

Abrupt increase in the blood pressure, leading to an acute disruption of the blood-brain barrier, causing the brain to swell is the triggering event. Parietal and occipital lobes are most commonly involved, followed in-frequently by frontal lobes, the inferior temporal- occipital junction, and the cerebellum. ${ }^{6}$ Focal patchy areas of vasogenic edema due to PRES may also be seen in the basal ganglia, brainstem, deep white matter and internal capsule. ${ }^{[7]}$ Myogenic and neurogenic component form the cerebral auto-regulatory mechanism which maintains constant brain perfusion. Effectiveness of neurogenic component is directly proportional to degree of sympathetic innervation. To maintain constant perfusion, vasoconstriction occurs in response to hypertension via sympathetic innervations of the cerebral vessels. Sudden increase in BP, overcomes auto-regulatory capability of brain vasculature leading to abrupt dilatation of cerebral arterioles. Hyper-perfusion ensues. Breakdown of blood brain barrier causes petechial haemorrhages. Focal transudation of fluid into interstitium results in vasogenic edema. Posterior circulation is thought to be more susceptible to this type of damage, because there is less sympathetic innervation of the vertebrobasilar vasculature to protect the parenchyma from rapid increases in arterial blood pressure. ${ }^{11,12}$

On MRI, T1-weighted images show hypo-intense and T2weighted images show hyper-intense areas. ${ }^{8}$ The typical imaging findings of PRES are most apparent as hyperintensity on FLAIR images in the parieto-occipital and posterior frontal cortical and subcortical white matter, less commonly brain stem, basal ganglia and cerebellum are involved. Atypical imaging appearances include contrast enhancement, hemorrhage and restricted diffusion on MRI. ${ }^{9}$ PRES lesions involving the occipital lobe spare the calcarine and para-median occipital lobe. This feature, along with the predominant involvement of white matter helps to distinguish this syndrome from bilateral infarctions of the posterior cerebral artery. ${ }^{1}$ When regions of the brain other than the parietooccipital lobes are predominantly involved, the syndrome can be called atypical. In such cases, a diffusion weighted MRI with ADC (increased apparent diffusion coefficient) mapping shows increased ADC values representing vasogenic edema in these areas, thus differentiating atypical PRES from other brain disorders. ${ }^{10}$ Diffusionweighted imaging may also help distinguish vasogenic edema (increased apparent diffusion coefficient) from cytotoxic edema (reduced apparent diffusion coefficient), seen in acute arterial ischemic injury. Magnetic resonance angiography using 3D Time of flight (TOF) technique, reversible "vasculopathy" (diffuse/focal vasoconstriction) or vessel pruning is noted. ${ }^{5}$

Treatment of elevated blood pressure is considered central in the management of PRES. Generally, the goal of treatment is the reduction of mean blood pressure to premorbid levels. Aggressive intravenous antihypertensive therapy should commence immediately, $\mathrm{BP}$ to be closely monitored, with an arterial catheter. IV Nicardipine $(5-15 \mathrm{mg} / \mathrm{h})$ and Labetalol $(2-3 \mathrm{mg} / \mathrm{min})$ are considered first-line medications in PRES. ${ }^{13}$

When the under-lying cause of PRES is treated effectively, MRI lesions shows resolution, unless the condition unfortunately, progresses to infarction or hemorrhage. ${ }^{1}$

\section{CONCLUSION}

Strong clinical suspicion and MRI, being the goldstandard, helped us to arrive at the diagnosis of PRES, a serious and potentially lethal condition. Further, we could distinguish PRES from other neurological conditions. MRI helped in the prompt diagnosis and early intervention. The disease was halted in the reversible stage. MRI, then, is the best available diagnostic modality inpatients with cerebral signs and symptoms complicating pregnancy further permitting early intervention. 


\section{REFERENCES}

1. Hinchey J, Chaves C, Appignani B, Breen J, Pao L, Wang A, et al. A reversible posterior leukoencephalopathy syndrome. Engl J Med. 1996;334:494-500.

2. Bartynski WS, Boardman JF. Distinct imaging patterns and lesion distribution in posterior reversible encephalopathy syndrome. AJNR Am J Neuroradiol. 2007;28:1320-7.

3. Casey SO, Sampaio RC, Michel E, Trwit CL. Posterior reversible encephalopathy syndrome: Utility of fluid-attenuated inversion recovery MR imaging in the detection of cortical and subcortical lesions. Am J Neuroradiol. 2002;21:1199-206.

4. Lee VH, Wijdicks EF, Manno EM, Rabinstein AA. Clinical spectrum of reversible posterior leukoencephalopathy syndrome. Arch Neurol 2008; 65:205-10.

5. Bartynski WS, Boardman JF, Zeigler ZR, Shadduck RK, Lister J. Posterior reversible encephalopathy syndrome in infection, sepsis, and shock. AJNR Am J Neuroradiol 2006; 27:2179-90.

6. Truwit CL, Denaro CP, Lake JR, De Marco T. MR Imaging of reversible cyclosporin A - induced neurotoxicity. AJNR Am J Neuroradiol 1991; 12: 651-9.
7. Covarrubias DJ, Luetmer PH, Campeau NG. Posterior reversible encephalopathy syndrome: prognostic utility of quantitative diffusion-weighted MR images. AJNR Am J Neuroradiol 2002; 23: 1038-48.

8. Al-Ansari M, Todwal A. A 20-year-old man with status epilepticus and uncontrolled hypertension. Chest 2007; 131: 309-12.

9. Schwartz RB, Mulkern RV, Gudbjartsson H, Jolesz F. Diffusion weighted MR imaging in hypertensive encephalopathy: clues to pathogenesis. AJNR Am J Neuroradiol 1998; 19: 859-62.

10. Bianco F. Reversible posterior leukoencephalopathy syndrome: a changing concept. Neuroradiology 2005; 47: 703-4.

11. Vaughan CJ, Delanty N. Hypertensive emergencies. Lancet. 2000;356:411-17.

12. Witlin AG, Friedman SA, Egerman RS, Frangieh AY, Sibai BM. Cerebrovascular disorders complicating pregnancy-beyond eclampsia. Am J Obstet Gynecol 1997; 176:1139-48.

13. Servillo G, Bifulco F, De Robertis E, et al. Posterior reversible encephalopathy syndrome in intensive care medicine. Intensive Care Med. 2007;33(2):230236.

DOI: $10.5455 / 2320-1770$. ijrcog20131245

Cite this article as: Valecha SM, Koshish SA, Gandhewar MR, Dhingra D. PRES in pregnancy: MRI and it's role in decision making. Int $J$ Reprod Contracept Obstet Gynecol 2013;2:701-3. 